\title{
A 10-Year Retrospective Analysis of Methyl Aminolevulinate Photodynamic Therapy Consultation at the Hospital de Braga
}

\author{
Celeste Brito $\cdot$ Cristina Resende $\cdot$ Pedro Oliveira
}

Received: February 23, 2016/ Published online: April 16, 2016

(C) The Author(s) 2016. This article is published with open access at Springerlink.com

\section{ABSTRACT}

Introduction: Photodynamic therapy (PDT) is a well-established treatment for actinic keratosis (AK), basal cell carcinoma (BCC), and Bowen's disease (BD). The object of this study was to describe the results of a retrospective analysis of patients treated with methyl aminolevulinate PDT (MAL-PDT) with red light, over the past decade at the Hospital de Braga (Braga, Portugal).

Methods: This study is based on the retrospective analysis of the clinical records of patients treated with MAL-PDT from January 2003 to December 2013.

Results: More than 550 patients with mean age of 72 years were treated with MAL-PDT. About

Enhanced content To view enhanced content for this article go to http://www.medengine.com/Redeem/ F4B4F06021CD60B4.

C. Brito $(\bowtie) \cdot$ C. Resende

Department of Dermatology and Venereology,

Hospital de Braga, Braga, Portugal

e-mail: dermcgb@gmail.com

P. Oliveira

EPIUnit/Instituto de Ciências Biomédicas, Abel

Salazar, ISPUP, Universidade do Porto, Porto,

Portugal two-thirds of these patients were female. In terms of diagnostics, $67 \%$ of the patient population were affected with AK, 27\% presented with BCC, and $4 \%$ had BD. With an average follow-up of 5.5 years, $99.5 \%$ of the lesions had cleared. The recurrence of lesions occurred during the first year of follow-up, mostly large BCC localized on the trunk.

Conclusion: This study showed the excellence of MAL-PDT for treating AK, BCC, and BD, with a low recurrence rate.

Keywords: Actinic keratosis; Basal cell carcinoma; Bowen's disease; Methyl aminolevulinate; Photodynamic therapy

\section{INTRODUCTION}

Photodynamic therapy (PDT) has been an important addition to the treatment modalities available to dermatologists [1-3]. Worldwide it is now a well-established and approved treatment option for actinic keratosis (AK) grade I, basal cell carcinoma (BCC), and also Bowen's disease (BD), with an acceptable tolerability profile and few reported complications [4-6]. 
The PDT effect is due to a type II photochemical reaction, which requires the presence of a photosensitizing molecule, photoactivating wavelengths of visible light, and tissue oxygen to generate singlet oxygen, which is highly reactive and initiates a series of reactions that culminate in necrosis and apoptosis.

Methyl aminolevulinate (MAL) associated to PDT (MAL-PDT) is approved for superficial skin malignancies such AK, BCC, and BD. MAL-PDT is a two-step procedure. In the first step, after a careful skin preparation, MAL is applied on the affected area and is allowed to be taken up by the skin. The application of MAL for $3 \mathrm{~h}$ under occlusion leads to an accumulation of protoporphyrin IX (PpIX) in the target cells. The second step involves the activation of PpIX in the presence of oxygen by directing red light toward the target tissue. Because the photosensitizer is preferentially absorbed by affected tissue and the light source is directly targeted on the lesion, PDT achieves dual selectivity, minimizing damage to adjacent healthy structures.

$\mathrm{AK}$ is a precancerous skin condition, which can progress to invasive squamous cell carcinoma (SCC) at a yearly rate of $0.075-0.096 \%$ per lesion [3]. Patients with higher risk of developing $\mathrm{AK}$ include the elderly, patients with lighter skin phototypes, and those with a history of chronic sun exposure $[2,3]$. AK can be treated with PDT on a lesion-by-lesion basis, or by applying a photosensitizer in a broad field of actinic damage, which allows concomitant treatment of subclinical AK [1-3]. Recently, it was shown in a retrospective analysis that direct invasion from proliferating grade I AK could be the most common form of progression to cutaneous invasive SCC [1].
Superficial BCC is a common skin tumor, with incidence increasing worldwide; it is commonly treated with surgical excision, curettage, or cryotherapy [4]. PDT has been widely used for the treatment of BCC in preference to excision, due to its minimal invasiveness and satisfactory cosmetic results $[3,4]$. Nonetheless, the efficacy of PDT monotherapy may be reduced in the treatment of deeper lesions ( $>2 \mathrm{~mm}$ depth) and more aggressive histological subtypes of BCC [4].

$\mathrm{BD}$ is considered an early stage or intraepidermal form of SCC [5]. PDT is recommended as the treatment of choice for both large and small plaques of $\mathrm{BD}$ at poor-healing sites and a good choice for large lesions at good-healing sites [7-9].

The results reported herein are a retrospective analysis of the clinical records of 583 patients who over the past decade were treated with MAL-PDT after being admitted in the PDT consultation at the Hospital de Braga, Braga, Portugal (henceforth referred to as "the institution"), a European excellence center for PDT, where this therapy is routinely used.

\section{METHODS}

This retrospective observational study was performed by analyzing the clinical records of patients treated with PDT at the institution, in the period from January 1, 2003 to December 31, 2013. Each patient was characterized in terms of age, gender, ethnicity, diagnosis, and number and size of lesions.

At baseline, dermatologic examination was performed in all patients with a clinical diagnosis of AK, BCC, or BD. Only patients with histological confirmation of superficial BCC or BD were included in the study. The diagnosis of AK was based only on clinical examination. The patients presenting nodular or morpheaform BCC were 
excluded. Informed consent was obtained from all patients before treatment with PDT. All procedures followed were in accordance with the ethical standards of the responsible committee on human experimentation (institutional and national) and with the Helsinki Declaration of 1964, as revised in 2013.

Prior to application of MAL cream, all lesions foreseen for treatment were prepared and crusts and scales were gently removed, always by a dermatologist experienced in PDT. Subsequently, a 1-mm-thick layer of MAL $160 \mathrm{mg} / \mathrm{g}$ cream was applied for $3 \mathrm{~h}$ under an occlusive film dressing. MAL was removed after $3 \mathrm{~h}$ incubation time and the skin was exposed to $630 \mathrm{~nm}$ red light from a diode lamp, with a total radiation dose of $37 \mathrm{~J} / \mathrm{cm}^{2}$ during $7 \mathrm{~min}$.

A protocol of two treatments performed 1 week apart for all lesions was used, this being one cycle. All patients were evaluated 3 months after the first cycle, and only if required they were submitted to a new cycle. Patients with complete resolution after the 3-month follow-up were further regularly checked during a follow-up of at least 12 months in the cases of $\mathrm{AK}$, and a minimum of 5 years in the cases of BCC and BD. The 5-year follow-up routine consisted of dermatologic consultations twice a year during the first 2 years after diagnosis and then every 12 months in the last 3 years. The recurrences of lesions were treated with an extra cycle of PDT or with conventional surgery. The record of every patient also included information about safety, tolerability, and satisfaction with PDT.

\section{RESULTS}

\section{Population}

In total, 583 patients were considered in the study and 1969 lesions were treated with
MAL-PDT. Of these patients, $62.6 \%(n=365)$ were female and $37.4 \%(n=218)$ were male. The mean age of the patients was 72.3 years (range 17-103 years). Patients were all of Caucasian origin. Furthermore, $67.4 \%$ $(n=393)$ were affected with AK, $28.6 \%$ $(n=167)$ presented BCC, and $2.7 \%(n=16)$ had BD. Figures 1 and 2 show two examples of patients treated with PDT.

\section{Type of Lesions}

With respect to the treated lesions, $79.1 \%$ $(n=1558)$ were AK $17.98 \% \quad(n=354)$ were BCC and $1.48 \%(n=23)$ were BD. All patients with AK had multiple lesions. Previous treatment modalities included keratolytics and cryotherapy.

\section{Location of Lesions}

The locations of treated $\mathrm{AK}$ lesions were predominantly on the face $(66.2 \%, n=1032)$ and on the bald scalp (12.5\%, $n=194$; Table 1$)$. BCC predominantly affected the face $(42.4 \%$, $n=150)$ and the trunk $(37.1 \%, n=131)$. BD predominantly affected the legs $(47.8 \%, n=11)$ and the face $(43.5 \%, n=10)$.

In female patients with $\mathrm{AK}$, the median age of the patients was 77 years. For BCC, the median age of the patients was 69 years. In the male patient population with $\mathrm{AK}$, the median age of the patients was 76 years, those with BCC had a median age of 68 years. It was statistically confirmed that the distribution of lesions by diagnosis was not independent of sex $\left(X^{2}=18.2 ; P<0.01\right)$.

In female patients, $72.1 \%(n=695)$ of $\mathrm{AK}$ and $50.8 \%(n=97)$ of BCC are located on the face. In male patients, $30.0 \%(n=175)$ of AK are located on the scalp and $41.1 \%(n=67)$ of BCC are located on the trunk (Fig. 3). It was also 

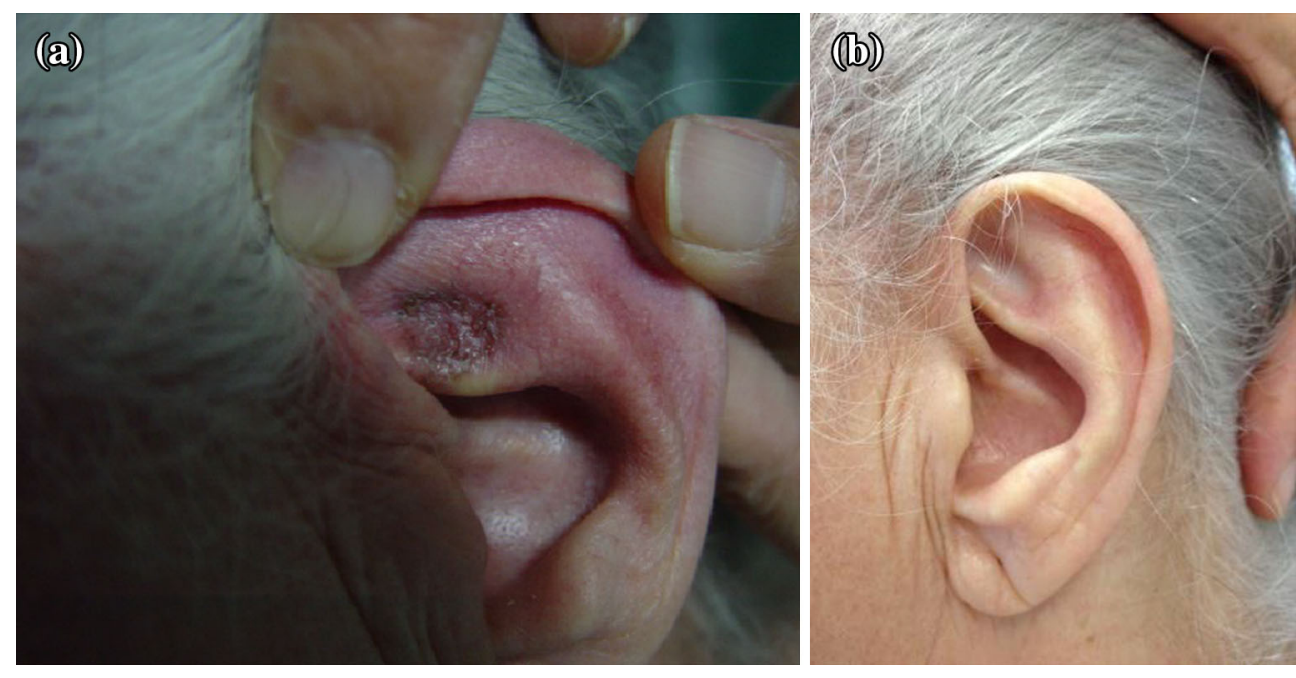

Fig. 1 A basal cell carcinoma localized on the antihelix of the ear and treated with photodynamic therapy. a Lesion before treatment. b Follow-up after 5 years
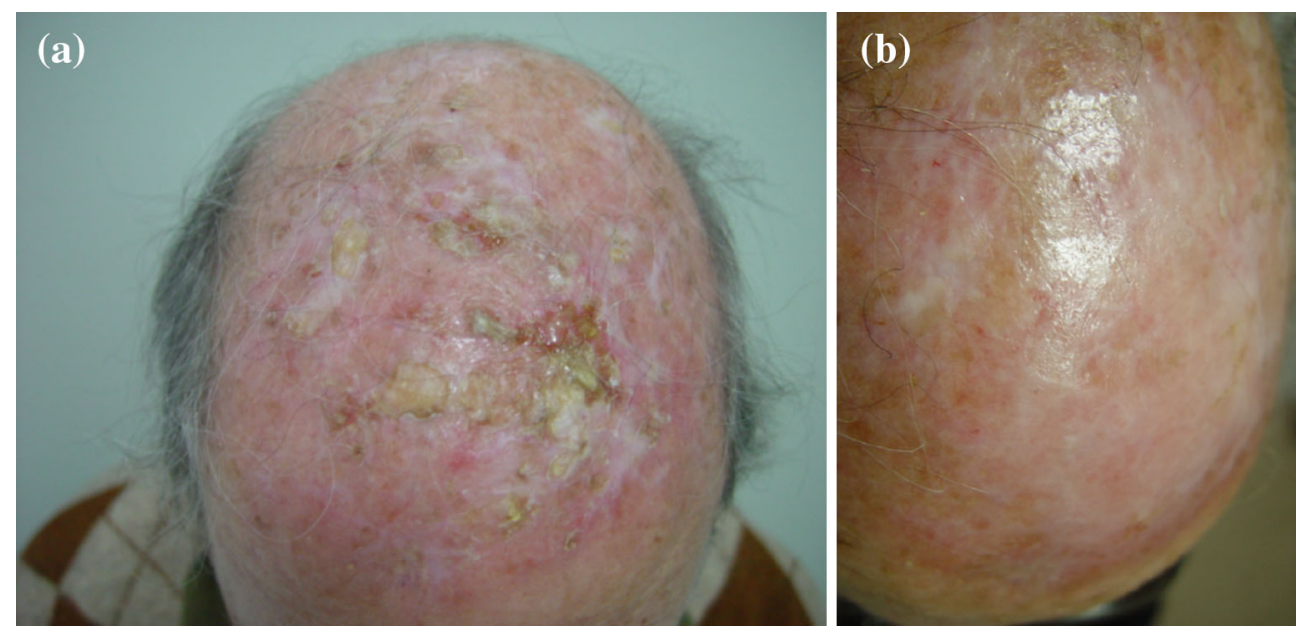

Fig. 2 Multiple actinic keratosis localized on the bald scalp and treated with photodynamic therapy. a Lesions before treatment. b Follow-up after 5 years

observed that the distribution of lesions by localization was not independent of sex in both cases of AK $\left(X^{2}=294.3 ; \quad P<0.001\right)$ and BCC $\left(X^{2}=18.9 ; P<0.01\right)$.

\section{Diagnosis of Lesions}

Among our cohort of patients, 546 had only 1 diagnosis and 37 had at least 2 diagnoses. In patients with multiple diagnoses, the most frequent association observed was $\mathrm{AK}$ and $\mathrm{BCC}$ in $86.5 \%(n=37)$. The size of the lesions in the period covered by this analysis was of median area of $25 \mathrm{~mm}^{2}$ in the cases of $\mathrm{AK}$ and $20 \mathrm{~mm}^{2}$ in BCC.

\section{Side Effects of PDT}

Apart from mild pain during the red light illumination, which was minimized by the 
Table 1 Lesions by location: cases (\%)

\begin{tabular}{lllllllll}
\hline & Location & \multicolumn{7}{c}{ Total } \\
\cline { 2 - 6 } & Face & Scalp & Trunk & Hands & Feet & Arms & Legs & \\
\hline AK & $1032(66.2)$ & $194(12.5)$ & $13(0.8)$ & $148(9.5)$ & $16(1.0)$ & $68(4.4)$ & $87(5.6)$ & $1558(100)$ \\
BCC & $150(42.4)$ & $27(7.6)$ & $131(37.1)$ & $2(0.6)$ & $7(1.98)$ & $23(6.5)$ & $14(3.95)$ & $354(100)$ \\
BD & $10(43.5)$ & $0(0.0)$ & $0(0.0)$ & $0(0.0)$ & $2(8.7)$ & $0(0.0)$ & $11(47.8)$ & $23(100)$ \\
Total & 1192 & 221 & 144 & 150 & 25 & 91 & 114 & 1935 \\
\hline
\end{tabular}

$A K$ actinic keratosis, $B C C$ basal cell carcinoma, $B D$ Bowen's disease

presence of a nurse and the soothing effect of an in-house-designed music program, there were no other adverse effects of PDT in the patients. All patients showed good compliance with the treatment and expressed signs of satisfaction.

\section{Follow-up}

With an average 5.5-year follow-up, $99.5 \%$ of the lesions were cleared and there was only a marginal $0.5 \%$ of recurrence of lesions all occurring during the first 6 months. The recurrence of all lesions occurred during the first year of follow-up and corresponded to large BCC localized on the trunk.

\section{DISCUSSION}

The large incidence of AK may be explained by the weather in Portugal, a country with a Mediterranean temperate climate, with many hours of sunshine, this being the major risk factor for the development of AK lesions. The predominant phototype in Portugal is phototype III [10]. These lesions when localized on the face and scalp respond well to PDT, with typical clearance rates of $89-92 \%$ [3-9]. The present guidelines for AK therapy recommend PDT being given as a single treatment and, if required, repeated 3 months later [9]. A good preparation of the lesions is important-removal of crusts and scalesbefore MAL cream application, which at the institution is always done by a PDT-experienced dermatologist.

PDT was used for the treatment of BCC, with a clearance rate in accordance with other studies, namely Morton et al. [9] who reported 92-97\%. In this study, it was found that the most frequent localization of $\mathrm{AK}$ in female patients was on the face and on the scalp for male patients. The excess of AK on the scalp in male patients is explained for many of these patients having a bald scalp, with a sun-damaged skin, a major risk factor for the development of AK. Individuals at higher risk of developing AK were elderly patients, which is also in accordance with the literature $[1,9,11$, 12].

PDT is an excellent treatment in the cases of large or multiple BCC because their growth pattern is primarily horizontal. Therefore, large scars and complications of conventional surgery are avoided, with good cosmetic results and high patient satisfaction $[9,12]$.

This is a retrospective study, with all limitations of a study of this type (e.g., the study population was not previously specified in terms of age and gender, and also social and professional background). Nevertheless, it has 

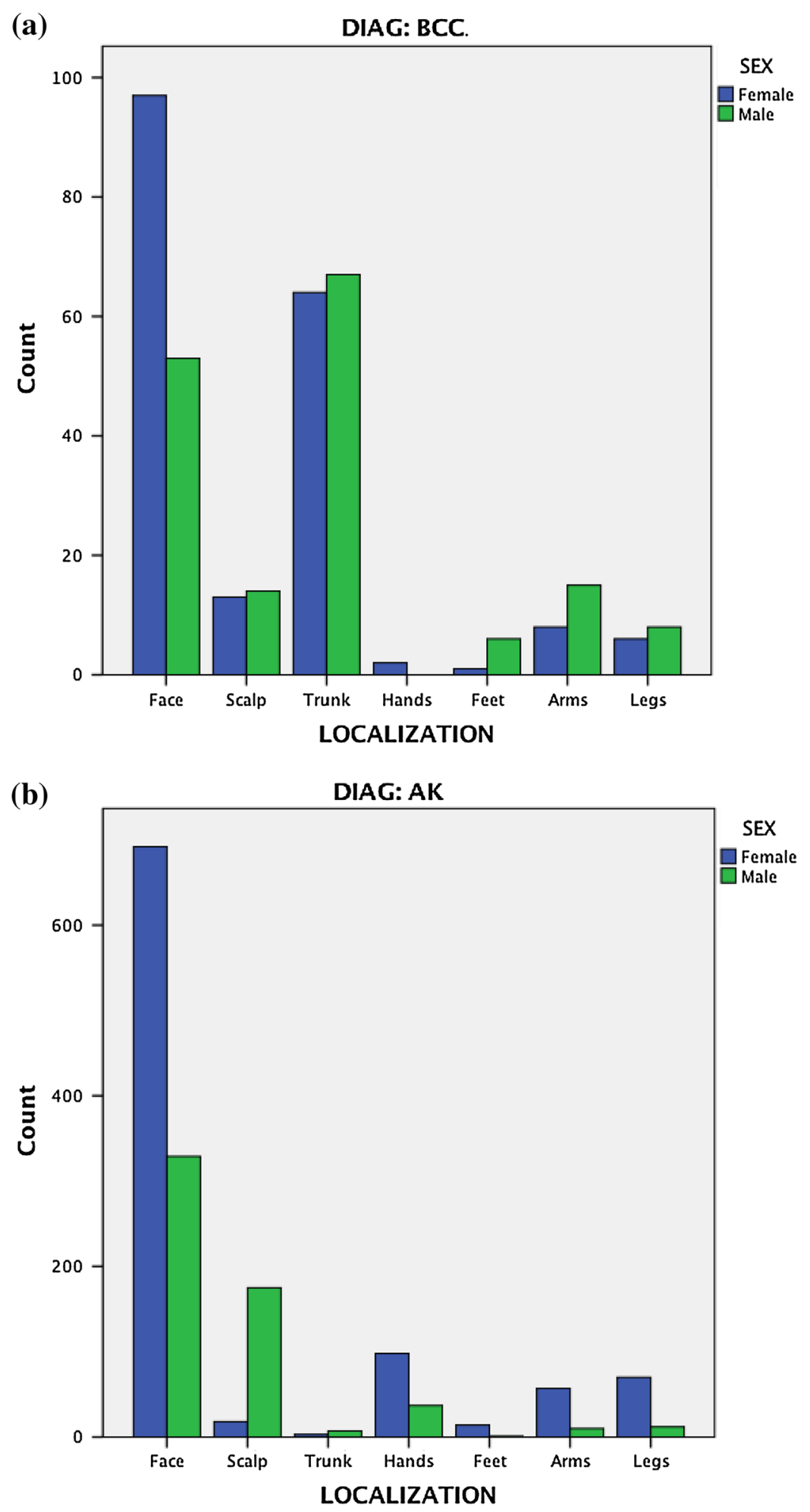

Fig. 3 Frequency distribution of $\mathbf{a} \mathrm{BCC}$ and $\mathbf{b} \mathrm{AK}$ in patients treated with PDT. $A K$ actinic keratosis, $B C C$ basal cell carcinoma 
the strength of being the presentation of the overall experience of a clinical department where PDT has been applied for over a decade.

\section{CONCLUSIONS}

This experience underlines the importance of a good selection of lesions being performed prior to PDT, all deeper lesions ( $>2 \mathrm{~mm}$ depth) being excluded. Also it is the requirement of a good preparation of lesions, including gentle removal of scales and crusts, which must always be done by a dermatologist with a prior experience with PDT. The excellent results of PDT during the period from 2003 to 2013 were apparent in a significant population of patients from the North of Portugal. In conclusion, MAL-PDT has been an essential part of the Hospital de Braga armamentarium in caring for patients with $\mathrm{AK}, \mathrm{BCC}$, and $\mathrm{BD}$, with excellent cosmetic results for the vast majority of them.

\section{ACKNOWLEDGMENTS}

No funding or sponsorship was received for this study. The article processing charges for this publication were funding by Associação dos Amigos do Serviço de Dermatologia do Hospital de S. Marcos, Braga, Portugal. All named authors meet the International Committee of Medical Journal Editors (ICMJE) criteria for authorship for this manuscript, take responsibility for the integrity of the work as a whole, and have given final approval for the version to be published. The final version of the manuscript was prepared with the assistance of Dr. S. Georgantopoulos from Galderma R\&D Sophia Antipolis. There was no financial involvement from Galderma.
Disclosures. Celeste Brito, Cristina Resende, and Pedro Oliveira have nothing to disclose.

Compliance with Ethics Guidelines. All procedures followed were in accordance with the ethical standards of the responsible committee on human experimentation (institutional and national) and with the Helsinki Declaration of 1964, as revised in 2013. Informed consent was obtained from all patients for being included in the study.

Open Access. This article is distributed under the terms of the Creative Commons AttributionNonCommercial 4.0 International License (http://creativecommons.org/licenses/by-nc/4. $0 /$ ), which permits any noncommercial use, distribution, and reproduction in any medium, provided you give appropriate credit to the original author(s) and the source, provide a link to the Creative Commons license, and indicate if changes were made.

\section{REFERENCES}

1. Fernández-Figueras MT, Carrato C, Sáenz X, Puig L, Musulen E, et al. Actinic keratosis with atypical basal cells (AK I) is the most common lesion associated with invasive squamous cell carcinoma of the skin. JEADV. 2015;29:991-7.

2. Calzavara-Pinton PG, Rossi MT, Sala R, Italian Group for Photodynamic Therapy. A retrospective analysis of real-life practice of off-label photodynamic therapy using methyl aminolevulinate (MAL-PDT) in 20 Italian dermatology departments. Part 2: oncologic and infectious indications. Photochem Photobiol Sci. 2013;12:158-65.

3. Criscione VD, Weinstock MA, Naylor MF, Lugue C, Eide MJ, et al. Actinic keratosis: natural history and risk of malignant transformation in the Veterans Affairs Tropical Tretinoin Chemoprevention Trial. Cancer. 2009;115:2523-30.

4. Trakatelli M, Morton C, Nagore E, Ulrich C, Del Marmol V. Update of the European guidelines for basal cell carcinoma management. Eur J Dermatol. 2014;24(3):312-29. 
5. Klein A, Babilas P, Karrer S, Landthaler M, Szeimies $\mathrm{RM}$, et al. Photodynamic therapy in dermatologyan update 2008. JDDG. 2008;6:839-45.

6. Babilas $\mathrm{P}$, Landthaler $\mathrm{M}$, Szeimies RM. Photodynamic therapy in dermatology. Eur J Dermatol. 2006;16:340-8.

7. Fai D, Arpaia N, Romano I, Vestita M, et al. Methyl-aminolevulinate photodynamic therapy for the treatment of actinic keratoses and non-melanoma skin cancers: a retrospective analysis of response in 462 patients. G Ital Dermatol Venereol. 2009;144:281-5.

8. Vergilis-Kalner IJ, Cohen JL. The use of photodynamic therapy as chemoprevention for the treatment of actinic keratoses and reduction in the number of non-melanoma skin cancers. J Drugs Dermatol. 2013;12:1085-6.

9. Morton CA, Szeimies RM, Sidoroff A, Braathen LR. European guidelines for topical photodynamic therapy part 1: treatment delivery and current indications-actinic keratoses, Bowen's disease, basal cell carcinoma. JEADV. 2013;27:536-44.

10. Brasileiro A, Campos S, Rocha-Páris F, Fidalgo A, Apetato M. Phototherapy in childhood: a 17-year retrospective study regarding effectiveness and safety. Presented at the 12th World Congress Pediatric Dermatology, Madrid, Spain. September 25-27, 2013.

11. Matei C, Tampa M, Poteca T, Panea-Paunica G, et al. Photodynamic therapy in the treatment of basal cell carcinoma. J Med Life. 2013;15:50-4.

12. Braathen LR, Szeimies RM, Basset-Seguin N, Bissonnette $\mathrm{R}$, et al. Guidelines on the use of photodynamic therapy for nonmelanoma skin cancer: an international consensus. International Society for Photodynamic Therapy in Dermatology, 2005. J Am Acad Dermatol. 2007;56:125-43. 